\title{
Clinical Reasoning: An Unexpected Response to Therapy in a Patient With HIV and Focal Seizures
}

\author{
Lorraine Chishimba, MBChB, MMED, Mashina Chomba, MBChB, MMED, Stanley Zimba, MBChB, MMED, \\ Tilele Mwansa, MBChB, MMED, Wilmot Sinyangwe, MBChB, Humphrey Kunda, MBChB, MMED, \\ Lottie Hachaambwa, MBChB, and Deanna Saylor, MD, MHS
}

Neurology ${ }^{\circledR}$ 2021;97:1084-1089. doi:10.1212/WNL.0000000000012536
Correspondence

Dr. Saylor

deanna@jhmi.edu

\begin{abstract}
We present the case of a 23-year-old right-handed man who presented to an emergency department in Lusaka, Zambia, with new-onset headaches and focal seizures. He was on combination antiretroviral therapy (cART) for HIV and had been started on antituberculous therapy at his local clinic 2 weeks before presentation, based on chest X-ray findings. On examination, he had subtle weakness and hyperreflexia in his left upper extremity. The remainder of the neurologic examination was normal. Brain CT scan revealed a single, ringenhancing, heterogenous mass in the right posterior parietal lobe with marked vasogenic edema. His laboratory results revealed severe virologic and immunologic failure, and CSF analysis was unremarkable. He was empirically managed as CNS tuberculosis (TB). Two months later, his symptoms worsened, and he developed new neurologic deficits, despite adherence to $\mathrm{CART}$ and $\mathrm{TB}$ treatment. Repeat imaging subsequently revealed progression of his underlying CNS process with multiple brain abscesses present, and subsequent investigations revealed an unusual cause of these lesions. In this case, we review the differential diagnosis for space-occupying lesions in the context of poorly controlled HIV infection. In particular, we highlight the approach to these patients in resource-limited settings in the context of diagnostic limitations and highlight the importance of considering the local epidemiology of neurologic infections. Finally, this case demonstrates the need to maintain a wide differential diagnosis and a close monitoring plan for prompt reevaluation of empiric diagnoses when response to empiric therapy is unexpected.
\end{abstract}

From the Department of Internal Medicine (L.C., M.C., L.H.), University of Zambia School of Medicine; Department of Internal Medicine (S.Z., T.M., L.H., D.S.), University Teaching Hospital; Department of Surgery (W.S., H.K.), University Teaching Hospital, Lusaka, Zambia; Division of Infectious Disease (L.H.), Department of Medicine, University of Maryland Medical Center; and Department of Neurology (D.S.), Johns Hopkins University School of Medicine, Baltimore, MD.

Go to Neurology.org/N for full disclosures. Funding information and disclosures deemed relevant by the authors, if any, are provided at the end of the article.

L. Chishimba and M. Chomba contributed equally to the work and should be considered co-first authors. 


\section{Section 1}

A 23-year-old right-handed man presented to a hospital in Lusaka, Zambia, with new-onset headaches and focal seizures involving his left arm, associated with impaired awareness and secondary generalization. He was on combination antiretroviral therapy (cART) for HIV composed of tenofovir, emtricitabine, and ritonavir-boosted lopinavir with a history of poor viral suppression. Antituberculous therapy (ATT) was started at his local clinic 2 weeks before presentation based on cough, fever, and chest radiograph findings suggestive of pulmonary tuberculosis (PTB). He had no other significant medical history. Examination revealed subtle weakness and hyperreflexia in his left arm.

\section{Questions for Consideration:}

1. What is the localization for his presentation?

2. What is the differential diagnosis?

3. What investigations can help narrow the diagnosis?

GO TO SECTION 2 


\section{Section 2}

This patient presented with focal unaware seizures with secondary generalization and left arm weakness suggestive of a right frontoparietal cortical lesion, likely due to a space-occupying lesion. Given his HIV status, a CNS opportunistic infection (CNS OI) was highly suspected. The most common causes of CNS OIs presenting as spaceoccupying lesions in people with HIV (PWH) include toxoplasmosis, cryptococcomas, and progressive multifocal leukoencephalopathy, all of which typically occur with $\mathrm{CD}^{+}$T-cell counts $<100$ cells $/ \mu \mathrm{L}$. Primary CNS lymphoma, which is associated with Epstein-Barr virus infection, is also possible, typically occurring at $\mathrm{CD} 4^{+} \mathrm{T}$-cell counts $<50$ cells $/ \mu \mathrm{L} .{ }^{1}$ In addition, in countries such as Zambia with a high burden of tuberculosis (TB), CNS TB presenting as a tuberculoma or tuberculous abscess must also be considered at virtually any $\mathrm{CD} 4^{+} \mathrm{T}$-cell count. ${ }^{1}$ Neuroimaging characteristics and CSF (if not precluded by neuroimaging findings) may be helpful in further narrowing the differential diagnosis in new-onset seizures in $\mathrm{PWH}$.

The patient's brain CT scan revealed a single, ring-enhancing, heterogenous mass in the right posterior parietal lobe with marked vasogenic edema. Full blood count revealed leukopenia. The metabolic panel was normal. CSF analysis showed 2 white cells, normal glucose, negative India ink stain, and negative cryptococcal antigen and toxoplasma antibody tests. Because of resource constraints, CSF protein and viral PCRs were unavailable. The normal CSF white cell count was believed to reflect failure to mount an inflammatory response in the setting of severe immunosuppression, as evidenced by the very low CD4 T-cell count and leukopenia. TB PCR was negative in both CSF and sputum. Plasma HIV viral load and $\mathrm{CD} 4{ }^{+} \mathrm{T}$-cell count were 9,207 cells $/ \mathrm{mL}$ and $1 / \mathrm{mm}^{3}$, respectively. Serum rapid plasma reagin was negative.

\section{Question for Consideration:}

1. How do these results change your differential diagnosis? 


\section{Section 3}

Infectious causes of ring-enhancing lesions in immunocompromised individuals not mentioned earlier include pyogenic brain abscess, fungal granuloma, and neurocysticercosis. Noninfectious etiologies include brain tumors, metastasis, glioblastoma, radiation necrosis, cortical vein thrombosis, intraparenchymal hemorrhage/resolving hematoma, and infarcts. However, the profound immunocompromised state kept CNS OIs at the top of the differential diagnosis. The negative CSF cryptococcal antigen made this less likely. Although toxoplasmosis typically occurs in the basal ganglia, ring-enhancing lesions in the corticomedullary junctions of the frontal and parietal lobes are not uncommon. However, seroprevalence for Toxoplasma gondii antibodies is low in subSahara Africa, suggesting low levels of infection. ${ }^{2}$

Given his recent PTB diagnosis, the high burden of TB in Zambia, the common clinical scenario in which CNS tuberculomas paradoxically develop after initiation of $\mathrm{ATT}^{3}$ and the notoriously low sensitivity of $\mathrm{TB}$ diagnostics in CSF (sensitivity range $\sim 30 \%-70 \%$ ), a working diagnosis of disseminated TB with CNS involvement was made. This is not an uncommon scenario in low-resourced settings with a high burden of both TB and HIV because HIV infection increases the risk of acquiring TB by 20 -fold. In Zambia, CNS TB occurs in approximately $10 \%$ of $\mathrm{PWH}^{4}$ Moreover, tuberculomas are a common cause of space-occupying brain lesions in these settings, although confirming CNS TB is often challenging. ${ }^{5}$ High-dose oral prednisolone was added to his ATT with a planned taper over 4 weeks, carbamazepine treatment commenced, and his cART regimen was changed in consultation with infectious diseases specialists, given virologic failure. Although concern for immune reconstitution inflammatory syndrome (IRIS) emerging on the new cART regimen existed, the change in his CART was not delayed because existing data suggest that early optimization of CART in the setting of TB coinfection improves outcomes. This is in contradistinction to CNS OIs like cryptococcal meningitis in which delayed optimization and/or initiation of cART is associated with improved outcomes because of reduced rates of IRIS.

The patient's symptoms initially improved. However, 2 months later, he presented with severe headache, right eye ptosis, and vomiting despite adherence to ATT and cART.

\section{Questions for Consideration:}

1. What is the differential diagnosis for the worsening symptoms and new neurologic deficits?

2. What investigations would help arrive at a diagnosis?

GO TO SECTION 4 


\section{Section 4}

In the presence of ATT, continuous progression of tuberculomas is unlikely, though not impossible. A new OI resulting from IRIS is also possible, given his very low $\mathrm{CD} 4^{+}$ T-cell count at presentation and the change in cART. However, given the significant vasogenic edema on initial imaging, the initial improvement could also be attributed to

\section{Figure 1 Brain CT Scan}

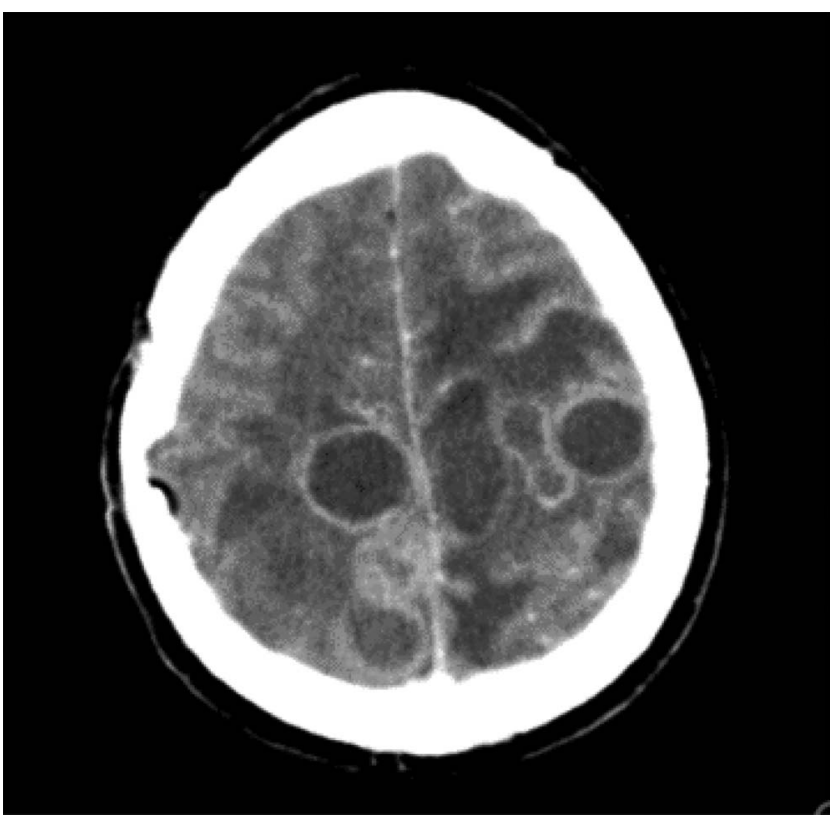

Contrast-enhanced brain computed tomography (CT) scan showing multiple, well-circumscribed, bihemispheric, contrast-enhanced, hypodense lesions.

corticosteroids rather than the antimicrobial therapy with tapering of steroids leading to worsening symptoms. Given the focal findings, brain imaging was indicated, but MRI was not immediately available in our setting.
Figure 2 Brain MRI Scan

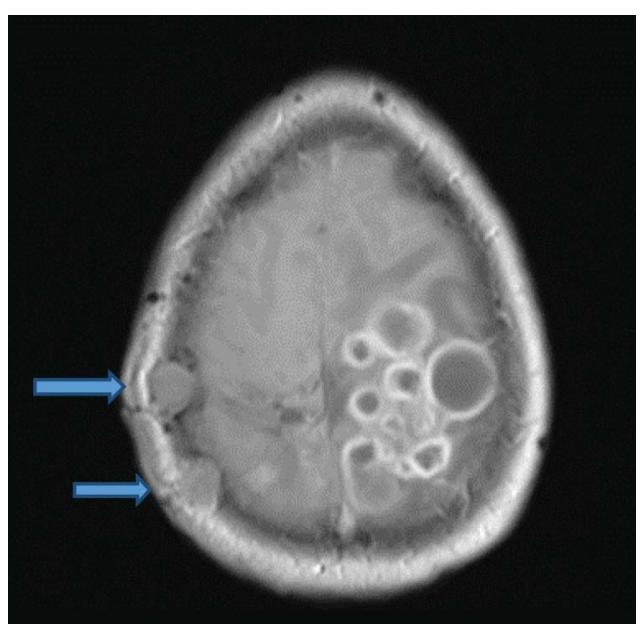

Contrast-enhanced brain magnetic resonance imaging (MRI) scan showing multiple, well-circumscribed, hypointense lesions and 2 extradural lesions along drainage tracts (arrows).

Repeat brain CT revealed 3 new brain abscesses. Given continued progression in the setting of empiric therapy, he underwent neurosurgical drainage through burr hole. Microbiological studies were negative. He was empirically initiated on a 4-week cefotaxime course with some improvement. Six weeks later, however, he developed worsening headaches and vomiting. The CT scan again showed multiple new brain abscesses (Figure 1), and a second burr hole was undertaken. Two weeks later, he developed breakthrough seizures and right-sided hemiparesis. Brain MRI revealed $>10$ abscesses, primarily in the left parieto-occipital lobe with 2 extradural lesions along previous neurosurgical tracts (Figure 2) with perilesional edema and left uncal herniation.

\section{Question for Consideration:}

1. What is the differential diagnosis for continued progression despite empiric antituberculous and antibiotic therapies in a severely immunocompromised $\mathrm{PWH}$ ?

\section{GO TO SECTION 5}




\section{Section 5}

The worsening brain abscesses, despite satisfactory compliance to ATT, justified a need for review of the empiric clinical diagnosis. We considered other CNS infections that cause space-occupying lesions in immunocompromised individuals, including fungal infections caused by Aspergillus sp., Blastomyces sp., Histoplasma sp., and Coccidioides sp.- - whose clinical presentations include brain abscesses, granulomas, and stroke syndromes ${ }^{6}$-and Nocardia sp., neurosyphilis, and Echinococcus sp., which can each present with multiple brain abscesses.

Microscopy of the sample collected during the second drainage identified Nocardia species. The patient was started on high-dose trimethoprim-sulfamethoxazole (TMP-SMX) for 12 months. He was also treated with a 10-day course of meropenem and then transitioned to amoxicillin/clavulonate because of resource limitations for meropenem. He improved clinically to the point that his neurologic examination normalized, his seizures stopped, and imaging showed a reduction in the number of abscesses by the third month of treatment. Clinical response has now been sustained for $>1$ year.

Of note, our patient had developed respiratory symptoms before the onset of neurologic symptoms, which were empirically treated as PTB. Although it is possible that these were due to Nocardia sp., resolution of his respiratory symptoms with ATT suggests that he likely had a coinfection with tuberculosis, which is not uncommon in the setting of advanced HIV infection.

\section{Discussion}

Nocardiosis is an infection that commonly affects immunocompromised individuals, ${ }^{7}$ although one-third of patients are immunocompetent. Of note, it is believed to be uncommon in PWH because of TMP-SMX prophylaxis for pneumocystis pneumonia. ${ }^{8}$

Nocardia sp. are weakly Gram-positive, acid-fast, filamentous, branching aerobic bacilli. Nocardiosis manifests as a single-organ or multifocal disease, with the lung followed by the CNS being the most common sites. ${ }^{9}$ Most cases of CNS disease present with ring-enhancing lesions but are often misdiagnosed as tuberculosis, tumors, or other kinds of abscesses due to the low specificity of neuroimaging findings for Nocardia sp. ${ }^{10}$ In this case, the continued progression of lesions despite ATT made them less likely to be tuberculosis. Signs and symptoms are nonspecific and include focal neurologic deficits, confusion, fevers, headaches, and seizures. ${ }^{10}$ Diagnosis requires abscess drainage and culture. The drug of choice is TMP-SMX for 12 months because it has good CNS penetration and is associated with lower mortality rates. ${ }^{11}$ In high-resourced settings, it is combined with a carbapenem such as meropenem or imipenem, and the combination is continued until clinical improvement occurs and Nocardia species identification and antimicrobial drug susceptibility information can be confirmed. ${ }^{11}$

In low-resourced settings, with limited access to CSF diagnostics, establishing a definitive diagnosis of a CNS infection is often challenging because established algorithms often require diagnostic investigations unavailable in these settings. Epidemiology of infectious etiologies also differs by region, with $\mathrm{TB}$ occurring more commonly in lowresourced settings. Therefore, many patients are managed presumptively based on the prevailing local epidemiology, and after other likely etiologies have been excluded with the available workup. With this backdrop, maintaining a wide differential diagnosis and developing a close monitoring plan become key to promptly reevaluating empiric diagnoses when the response to empiric therapy is unexpected, as demonstrated in this case.

\section{Study Funding}

United States Department of State Fulbright Scholar Award (Saylor).

\section{Disclosure}

L. Chishimba, M. Chomba, S. Zimba, T. Mwansa, W. Sinyangwe, H. Kunda, and L. Hachaambwa report no disclosures relevant to this manuscript. D. Saylor received funding from the United States Department of State. Go to Neurology. org/ $\mathrm{N}$ for full disclosures.

\section{References}

1. Siddiqi OK, Elafros MA, Bositis CM, et al. New-onset seizure in HIV-infected adult Zambians: a search for causes and consequences. Neurology. 2017;88(5):477-482.

2. Dotchin CL, Msuya O, Walker RW, et al. Seroprevalence and determinants of toxoplasmosis in pregnant women attending antenatal clinic at the university teaching hospital, Lusaka, Zambia. Mov Disord. 2017;36(2):10.

3. Das A, Das SK, Mandal A, Halder AK. Cerebral tuberculoma as a manifestation of paradoxical reaction in patients with pulmonary and extrapulmonary tuberculosis. J Neurosci Rural Pract. 2012;3(3):350-354.

4. Berenguer J, Moreno S, Laguna F, et al. Tuberculous meningitis in patients infected with the human immunodeficiency virus. N Engl J Med. 1992;326(10):668-672.

5. Oncul O, Baylan O, Mutlu H, Cavuslu S, Doganci L. Tuberculous meningitis with multiple intracranial tuberculomas mimicking neurocysticercosis clinical and radiological findings. Jpn J Infect Dis. 2005;58(6):387-389.

6. Raman Sharma R. Fungal infections of the nervous system: current perspective and controversies in management. Int J Surg. 2010;8(8):591-601.

7. Anagnostou T, Arvanitis M, Kourkoumpetis TK, Desalermos A, Carneiro HA, Mylonakis E. Nocardiosis of the central nervous system: experience from a general hospital and review of 84 cases from the literature. Med (Baltimore). 2014;93(1):19-32.

8. Pintado V, Gómez-Mampaso E, Cobo J, et al. Nocardial infection in patients infected with the human immunodeficiency virus. Clin Microbiol Infect. 2003;9(7):716-720.

9. Rafiei N, Peri AM, Righi E, Harris P, Paterson DL. Central nervous system nocardiosis in Queensland: a report of 20 cases and review of the literature. Med (Baltimore). 2016;95(46):e5255.

10. Brown-Elliott BA, Brown JM, Conville PS, Wallace RJ Jr. Clinical and laboratory features of the Nocardia spp. based on current molecular taxonomy. Clin Microbiol Rev. 2006;19(2):259-282.

11. Wilson JW. Nocardiosis: updates and clinical overview. Mayo Clin Proc. 2012;87(4): 403-407. 


\section{Neurology}

\section{Clinical Reasoning: An Unexpected Response to Therapy in a Patient With HIV and Focal Seizures \\ Lorraine Chishimba, Mashina Chomba, Stanley Zimba, et al.}

Neurology 2021;97;1084-1089 Published Online before print July 26, 2021

DOI 10.1212/WNL.0000000000012536

This information is current as of July 26, 2021

\section{Updated Information \& Services}

\section{References}

Subspecialty Collections

\section{Permissions \& Licensing}

Reprints including high resolution figures, can be found at: http://n.neurology.org/content/97/23/1084.full

This article cites 11 articles, 2 of which you can access for free at: http://n.neurology.org/content/97/23/1084.full\#ref-list-1

This article, along with others on similar topics, appears in the following collection(s):

\section{Abscess}

http://n.neurology.org/cgi/collection/abscess

All Clinical Neurology

http://n.neurology.org/cgi/collection/all_clinical_neurology

All global neurology

http://n.neurology.org/cgi/collection/all_global_neurology

All Infections

http://n.neurology.org/cgi/collection/all_infections

Training-international

http://n.neurology.org/cgi/collection/training_international

Information about reproducing this article in parts (figures,tables) or in its entirety can be found online at:

http://www.neurology.org/about/about_the_journal\#permissions

Information about ordering reprints can be found online:

http://n.neurology.org/subscribers/advertise

Neurology ${ }^{\circledR}$ is the official journal of the American Academy of Neurology. Published continuously since 1951, it is now a weekly with 48 issues per year. Copyright @ 2021 American Academy of Neurology. All rights reserved. Print ISSN: 0028-3878. Online ISSN: 1526-632X.

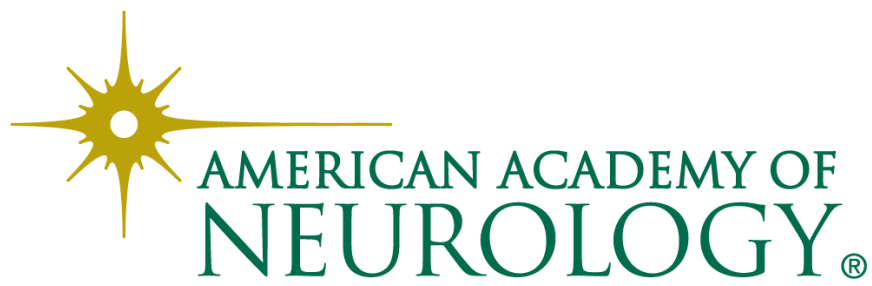

